\title{
Towards a Computational Fluid Dynamics-Based Fuzzy Logic Controller of the Optimum Windcatcher Internal Design for Efficient Natural Ventilation in Buildings
}

\author{
Ashraf Balabel $\mathbb{D}^{\mathrm{D}},{ }^{1}$ Mohammad Faizan, ${ }^{2}$ and Ali Alzaed ${ }^{3}$ \\ ${ }^{1}$ Mechanical Engineering Department, Taif University, Taif, Saudi Arabia \\ ${ }^{2}$ Mechanical Engineering Department, Aligarh Muslim University, Aligarh, India \\ ${ }^{3}$ Architectural Engineering Department, Taif University, Taif, Saudi Arabia \\ Correspondence should be addressed to Ashraf Balabel; a.balabel@tu.edu.sa
}

Received 8 March 2021; Revised 23 March 2021; Accepted 29 March 2021; Published 12 April 2021

Academic Editor: G. Muhiuddin

Copyright (C) 2021 Ashraf Balabel et al. This is an open access article distributed under the Creative Commons Attribution License, which permits unrestricted use, distribution, and reproduction in any medium, provided the original work is properly cited.

Recently, increased attention has been given to the coupling of computational fluid dynamics (CFD) with the fuzzy logic control system for obtaining the optimum prediction of many complex engineering problems. The data provided to the fuzzy system can be obtained from the accurate computational fluid dynamics of such engineering problems. Windcatcher performance to achieve thermal comfort conditions in buildings, especially in hot climate regions, is considered as one such complex problem. Windcatchers can be used as natural ventilation and passive cooling systems in arid and windy regions in Saudi Arabia. Such systems can be considered as the optimum solution for energy-saving and obtaining thermal comfort in residential buildings in such regions. In the present paper, three-dimensional numerical simulations for a newly-developed windcatcher model have been performed using ANSYS FLUENT-14 software. The adopted numerical algorithm is first validated against previous experimental measurements for pressure coefficient distribution. Different turbulence models have been firstly applied in the numerical simulations, namely, standard k-epsilon model (1st and 2nd order), standard Wilcox k-omega model (1st and 2nd order), and SST $\mathrm{k}$-omega model. In order to assess the accuracy of each turbulence model in obtaining the performance of the proposed model of the windcatcher system, it is found that the second order k-epsilon turbulence model gave the best results when compared with the previous experimental measurements. A new windcatcher internal design is proposed to enhance the ventilation performance. The fluid dynamics characteristics of the proposed model are presented, and the ventilation performance of the present model is estimated. The numerical velocity profiles showed good agreement with the experimental measurements for the turbulence model. The obtained results have shown that the second order k-epsilon turbulence can predict the different important parameters of the windcatcher model. Moreover, the coupling algorithm of CFD and the fuzzy system for obtaining the optimum operating parameters of the windcatcher design are described.

\section{Introduction}

In windy and arid regions of different countries worldwide and especially in Saudi Arabia, windcatchers can be considered as the optimum solution for energy-saving and obtaining indoor thermal comfort in a natural way. Previously, different shape designs of windcatchers have been proposed and tested either numerically or experimentally, and their ventilation performance has been evaluated. Extended reviews of different theoretical and experimental methods employed to evaluate the performance characteristics of windcatchers can be found in [1]. Recently, a comprehensive review to describe the heat recovery systems that are potentially combined with natural ventilation windcatchers has been carried out [2]. More recently, the effects on the windcatcher performance of different internal factors, such as geometry and design, and the external building features and the surrounding environment have been reviewed [3].

Computational fluid dynamics has recently received great attention in the numerical simulation of the windcatcher model design and performance. Different 
parameters have been found to have important effects on the obtained results, such as the resolution of the computational grid, the order of discretization scheme, and the turbulence model adopted. Most of the previous studies have been performed for 3D steady RANS for traditional two-sided windcatcher models [4]. Recently, the analysis of the internal flow characteristics of the traditional two-sided windcatcher model has been performed for a better understanding of the external flow condition effects on ventilation performance [5]. The numerical simulation has been carried out using the standard $\mathrm{k}-\varepsilon$ turbulence model. It is concluded that other turbulence models should be applied instead of the standard k-epsilon model, e.g., the SST model. More recently, sensitivity analysis of the traditional two-sided windcatcher model has been performed in order to improve the thermal comfort conditions [6]. A 3D steady CFD simulation along with a shear-stress-transport $\mathrm{k}-\omega$ turbulence model is applied for obtaining the windcatcher performance. The effect of introducing an internal windcatcher nozzle on the increased mass flow rate has been estimated.

Generally, it can be concluded from the previous literature that no investigations have been performed to study the effect of the internal design of the windcatcher model on the ventilation performance. Moreover, most of the previous CFD simulation has considered the known standard turbulence models. In our previous paper [7], an innovative modern design of the internal section of a four-sided windcatcher for natural ventilation in Saudi Arabia's buildings has been presented. The proposed model of the windcatcher can avoid most of the shortcomings of previous models presented in the literature in such a manner that the proposed model can harvest the incident wind from any direction. However, an estimation of the performance of the proposed model is required. It should be pointed out that the commercial ANSYS software has been applied previously in many important papers that investigated the performance of windcatcher in different flow regimes [5, 8-12].

In the present paper, computational fluid dynamics (CFD) for the proposed design of the windcatcher using ANSYS FLUENT-14 software is performed. Different turbulence models have been used firstly for validation of the numerical scheme. The verified model is then used for the following prediction of the windcatcher performance.

\section{The New Internal Design of Windcatcher}

The new design of the internal section of the windcatcher is illustrated in Figure 1. The illustrated design is assumed to overcome the limitations of the previous conventional windcatchers and improve their performance. The foursided wind tower is assumed to be exposed to the wind from all directions through four fixed openings. The internal design of each separated section is shown in Figure 1. Many limitations of the other models found in the literature can be eliminated by using the proposed design [13]. Moreover, this internal section is designed to increase the ventilation efficiency by using the known characteristics of aerodynamics in variable cross-section areas.
The Reynolds number of the incoming air is calculated according to the relation: $\operatorname{Re}=\rho V D_{\mathrm{h}} / \mu$, where $\rho$ is the air density, $V$ is the wind speed, $\mu$ is the dynamic viscosity, and $D_{\mathrm{h}}$ is the hydraulic diameter of the cross-section $\left(D_{\mathrm{h}}=4 *\right.$ area/perimeter $)$.

In the described design shown above, it is assumed that interior of the windcatcher is divided into four separated sections. Each section has a square opening with width $D_{\text {in }}$ in the normal direction of the incident wind. An inclined wall with an angle $\theta$ to the horizontal direction is used to direct the incoming wind to the interior space of the windcatcher. A horizontal flat plate with a one-side opening is fixed in the downstream of the wind direction. This flat plate can be adjusted according to the ratio of $L_{1} / L_{2}$ (see Figure 1 ).

This innovative design of the internal section of the windcatcher that receives the incident wind can lead to an increase of the wind velocity due to the convergent nozzle shape applied. After the streaming of the incoming air flow through the opening with width $L_{2}$, air pressure will increase due to the cross-section area expansion. Consequently, the air flow is directed to the building interior with high pressure, enabling uniform air distribution in a natural way. The model parameters, such as $\left(L_{1} / L_{2}, \theta\right)$ should be investigated along with the incoming wind Reynolds number to find out the optimum values of such parameters.

The problem will be addressed in this study using CFD techniques. The four-sided windcatcher, previously proposed by the authors in an earlier study [7] to harvest the wind flowing in any direction, is applied. In these ventilation setups, the air enters from suitable opening and flows through the building and lastly leaves through windows, doors, or other exhaust segments. In the present study, one side of the windcatcher is numerically simulated, which is a scaled model of the proposed setup. In this study, several modifications of the windcatcher will be explored and the effect of these alterations on the pressure recovery coefficient will be studied. In the present study, only one side of the windcatcher is modelled with the view that wind would be flowing in one direction with significant velocity at a given time.

\section{Computational Fluid Dynamics}

The three-dimensional computational model is set up to simulate the considered windcatcher geometry. Also, the boundary conditions and the model operating conditions are also defined. The solution is carried out using the commercial software ANSYS FLUENT-14. The computational domain along with the boundary conditions has been described as shown in Figure 2. A combination of structured and unstructured mesh was used for various sections of the model with approximately 450414 total nodes and 429300 elements. The model used very fine mesh near the wall and around the plate near the opening to capture the important flow behavior near the wall (i.e., $\mathrm{y}^{+}<5$ in the viscous sublayer). The upstream velocity was imposed to the inlet section of the model. 


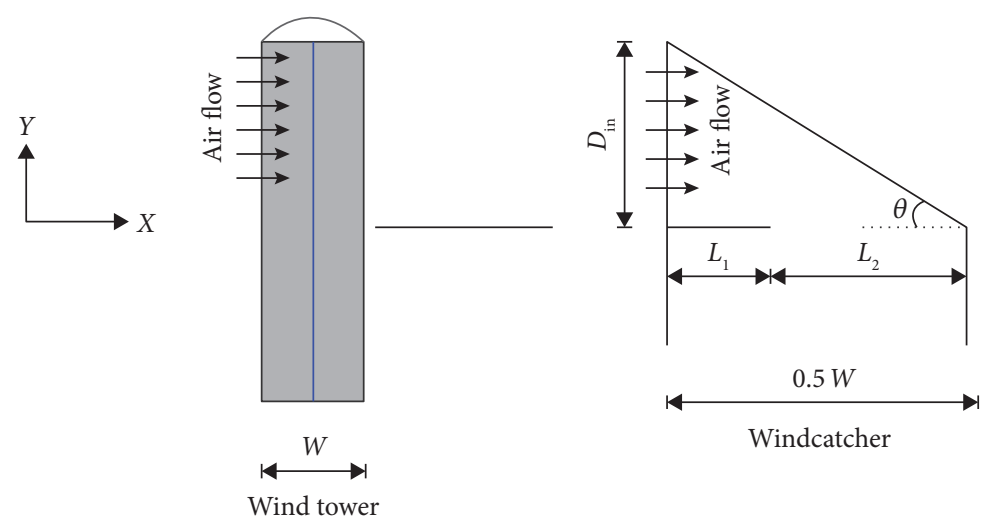

Figure 1: The proposed windcatcher and its geometrical parameters $\left(W=80 \mathrm{~mm}\right.$, Din $=W$ when $\left.\theta=45^{\circ}\right)$.

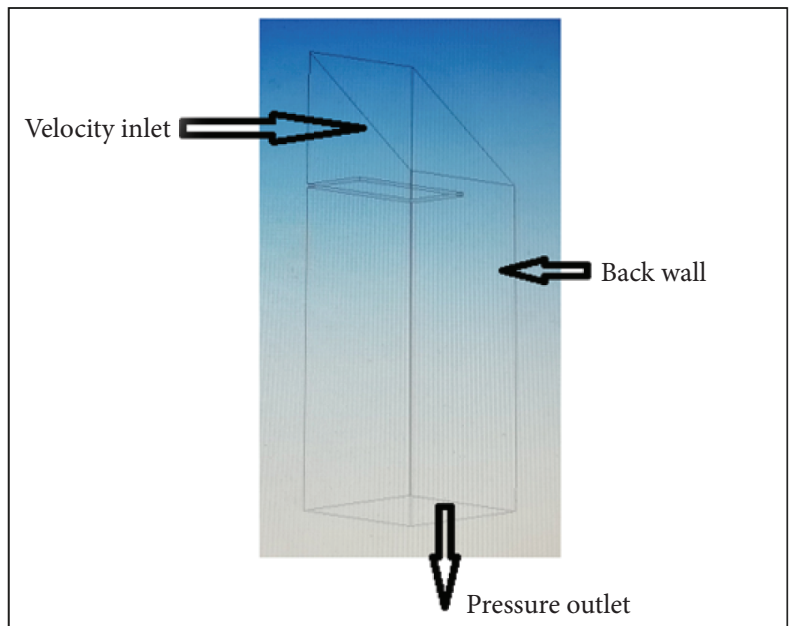

FIgURE 2: Computational domain and boundary conditions.

\section{Governing Equations}

The flow characteristics inside the proposed design of the windcatcher can be predicted by solving a set of the governing equations in the form of Reynolds-averaged Navier-Stokes equations, as follows:

4.1. Reynolds-Averaged Navier-Stokes Equations. The continuity and momentum equations for incompressible and steady turbulent flow, known as RANS equations, at each grid point of the flow field can be described by the following equations after omitting the body force:

$$
\begin{aligned}
\nabla \cdot(\rho \bar{u}) & =0, \\
\nabla \cdot(\rho \overline{u \mathcal{u}})+\nabla p & =\nabla \cdot\left(2 \mu \widehat{S}+\widehat{\mathfrak{R}}_{t}\right) .
\end{aligned}
$$

In the above system of equations, $p$ denotes the pressure, $\bar{u}$ is the velocity vector, and $\rho, \mu$ are the flow density and the molecular viscosity, respectively. The strain rate tensor is given by $\widehat{S}$, where the turbulent stress tensor is defined as

$$
\begin{aligned}
\widehat{S} & =0.5\left(\frac{\partial u_{i}}{\partial x_{j}}+\frac{\partial u_{j}}{\partial x_{i}}\right), \\
\widehat{\mathfrak{R}}_{t} & =-\rho \overline{u_{i}^{\prime} u_{j}^{\prime}}=-\frac{2}{3} \rho k \delta_{i j}+2 \mu_{t} S_{i j},
\end{aligned}
$$

where $\delta_{i j}$ is the Kronecker delta and is the average of the velocity fluctuations. The turbulent viscosity is defined as

$$
\mu=\frac{\rho c_{\mu} k^{2}}{\varepsilon} \text {. }
$$

The turbulent kinetic energy $k$ and its dissipation rate $\varepsilon$ can be calculated by solving the governing equations of the standard k-epsilon model, standard Wilcox k-omega model, and SST k-omega model. More descriptions about such models and their standards constants can be found in [14-16]. 


\section{Boundary Conditions}

For the problem under consideration, as it can be shown in Figure 2, three different boundary conditions have been described according to the options available in the commercial code used. The inlet boundary conditions describe the different characteristics of the incident wind, e.g., wind speed $(V)$, according to the Reynolds number considered. Moreover, the other relevant scalar properties of the flow are described according to the default values given in the commercial code. The pressure outlet boundary conditions require the value of the static atmospheric pressure at outlet boundary. For all walls in the geometry described in the computational domain, no slip boundary conditions have been assumed.

\section{Model Validation}

In order to validate the proposed numerical algorithm, a three-dimensional model was setup to replicate the experimental model of the one-sided windcatcher of Montazeri and Azizian [17]. The computational model was solved using commercial software, ANSYS FLUENT-14, imposing the same boundary and operating conditions as in the experimental study. Pressure recovery coefficient (Cp) was calculated on the back and side wall of the model. Different turbulence models were tried to get a comparative study to find out the best suited model for the windcatcher. The results on variation of $\mathrm{Cp}$ along the walls of the windcatcher using different models are illustrated in Figure 3. It is clearly seen in the figure that the second order $\mathrm{k}-\varepsilon$ model gives the best results when compared with the experimental data. It was therefore decided that the second order $\mathrm{k}-\varepsilon$ turbulent model will be used for further study on the windcatcher model.

\section{Results and Discussion}

The new model with the proposed modifications was tested numerically and pressure recovery coefficient was compared along the length of the windcatcher. The effect of changing the slab length, opening of the windcatcher, and Reynolds number was explored. For all cases, velocity contours, velocity streamlines, and velocity vectors were also compared.

7.1. Effect of Slab Length $\left(L_{1}\right)$. The slab length for the proposed windcatcher model was varied as $1 / 3,1 / 2$, and $2 / 3$ of the side of the square cross-section of the windcatcher. The baseline case of without slab was also included in the study. Figure 4 shows the variation of pressure coefficient $(\mathrm{Cp})$ at the middle of the back and side walls of the windcatcher. The $\mathrm{Cp}$ values are plotted along the length of the windcatcher where $Y=0$ represents the entry and $Y=0.1$ as the exit of the windcatcher. The pressure coefficient was high near the entry of the windcatcher and decreased along the length downward towards the exit. High value of $\mathrm{Cp}$ near the inlet indicates high pressure due to the presence of the slab which reduces the flow area, causing the nozzle effect. A similar phenomenon was observed at the side wall also, where $\mathrm{Cp}$ was also high near the inlet and remained nearly constant for most of the length of the windcatcher and slightly increased near the exit. Figure 5 shows the velocity contours for different slab lengths.

7.2. Effect of Windcatcher Opening $(\theta)$. The opening of the proposed windcatcher model to atmosphere was varied in terms of the slant angle as $\theta=30^{\circ}, 45^{\circ}$, and $60^{\circ}$. The slab length as $L_{1} / L_{2}=0.5$ was selected for this analysis. Figure 6 shows the variation of pressure coefficient $(\mathrm{Cp})$ at the middle of the back and side walls of the windcatcher. The Cp values are plotted along the length of the windcatcher where $Y=0$ represents the entry and $Y=0.1$ is the exit of the windcatcher. The pressure coefficient, as expected, was high near the entry of the windcatcher and decreased along the length downward towards the exit. It was interesting to note that the $\mathrm{Cp}$ value near the inlet increased when increasing the opening of the windcatcher. Increasing value of $\mathrm{Cp}$ with increasing opening indicates higher pressure which can be attributed to greater mass flow of air through increased windcatcher opening. A similar phenomenon was observed at the side wall also, where $\mathrm{Cp}$ was also high near the inlet and remained nearly constant for most of the length of windcatcher for all values of $\theta$. Figure 7 also shows the velocity contours for different slab lengths.

7.3. Effect of Reynolds Number (Re). The effect of Reynolds number was investigated by imposing three different inlet velocities viz. $5 \mathrm{~m} / \mathrm{s}, 10 \mathrm{~m} / \mathrm{s}$, and $15 \mathrm{~m} / \mathrm{s}$ in the windcatcher model. The slab length was $L_{1} / L_{2}=0.5$ and inlet opening was taken as $\theta=45^{\circ}$ for this analysis. The corresponding Reynolds numbers were $25,131,50,262$, and 75,393. Figure 8 shows the variation of pressure coefficient $(\mathrm{Cp})$ at the middle of the back and side wall of the windcatcher for different values of Re. The Cp values are plotted along the length of the windcatcher where $Y=0$ represents the entry and $Y=0.1$ as the exit of the windcatcher. The pressure coefficient, as expected, was high near the entry of the windcatcher and decreased along the length downward towards the exit. It was worth noting that the $\mathrm{Cp}$ variation along the length was not significantly changed when inlet velocity was increased from $10 \mathrm{~m} / \mathrm{s}$ to $15 \mathrm{~m} / \mathrm{s}$. A similar phenomenon was observed at the side wall also, where $\mathrm{Cp}$ was also high near the inlet and remained nearly constant for most of the length of the windcatcher for all values of Reynolds number. Figure 9 also shows the velocity contours for different slab lengths.

7.4. CFD-Based Fuzzy Logic Controller. As seen in the previous section, the numerical results obtained from the computational fluid dynamics of the proposed internal design of a windcatcher model are dependent on a number of operating parameters, namely, $L_{1} / L_{2}$ ratio, the angle $(\theta)$, and the Reynolds number (Re). Three different defined values of such operating parameters have been tested in order to show their effects on the windcatcher model performance. However, it is believed that a wide range of these operating parameters should be tested to obtain a group of values for these operating parameters. The fuzzy logic 


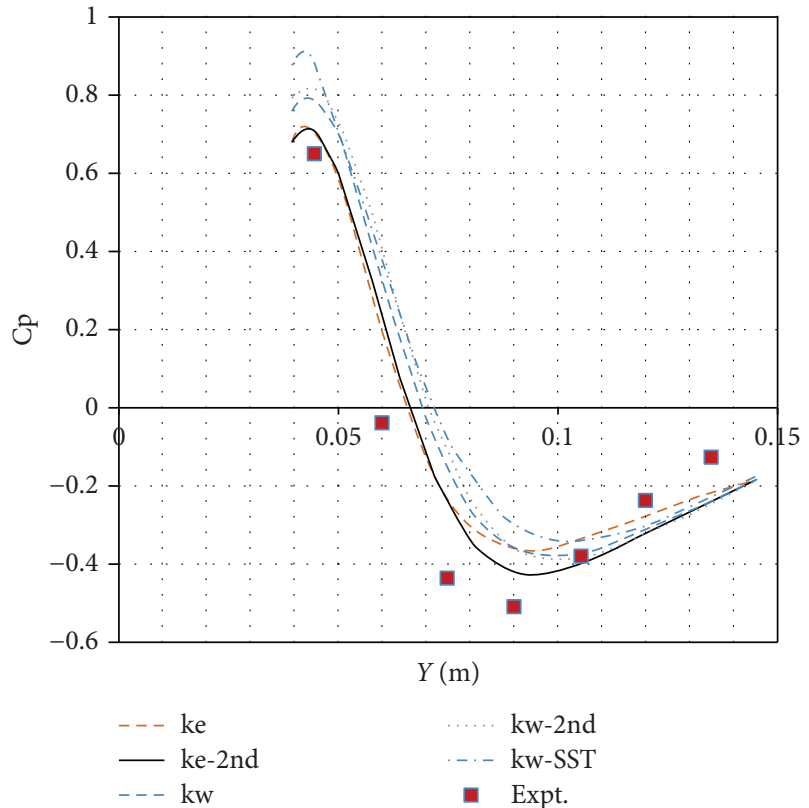

(a)

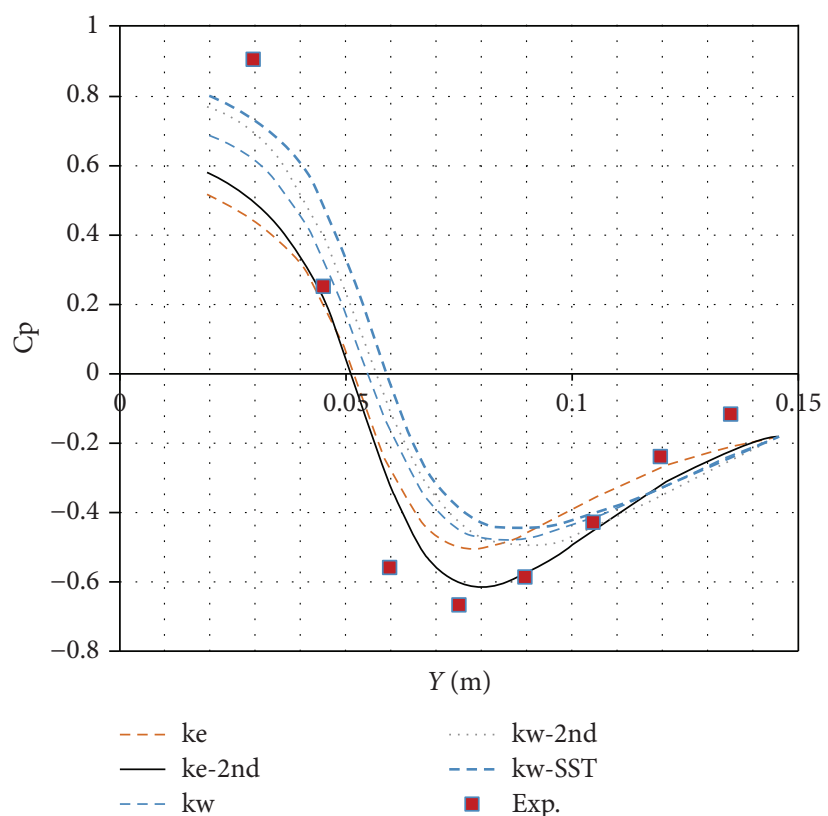

(b)

Figure 3: Comparison of different turbulent models with experimental data for pressure recovery coefficient (Cp) on (a) back wall and (b) side wall of windcatcher.

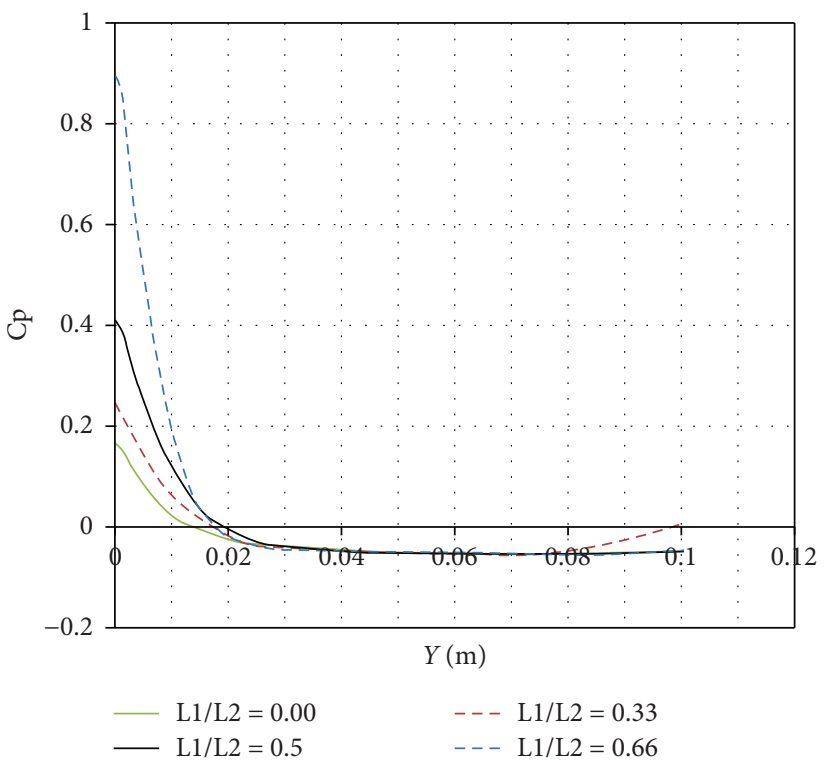

(a)

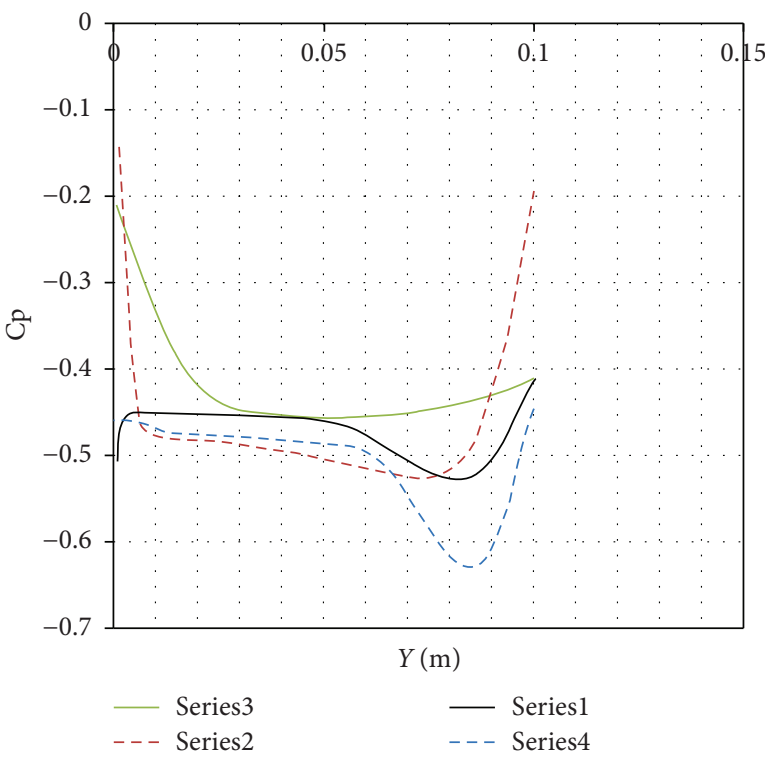

(b)

Figure 4: Effect of slab length $\left(L_{1}\right)$ on pressure recovery coefficient $(\mathrm{Cp})$ on (a) back wall and (b) side wall of windcatcher. 
Velocity

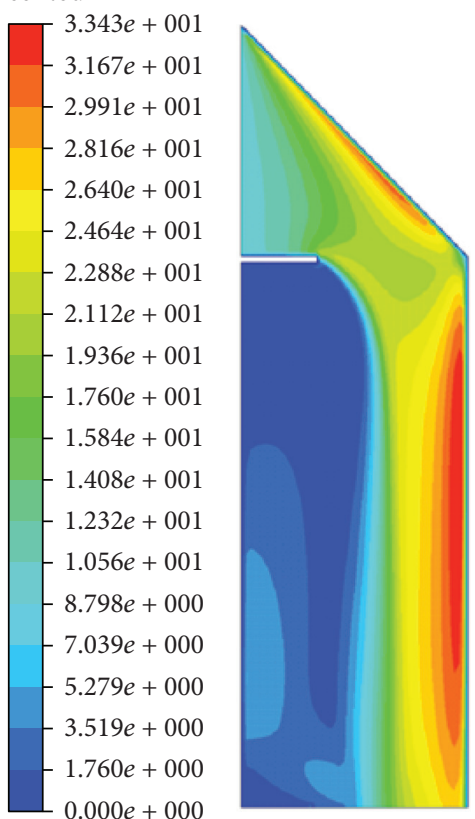

$\left(\mathrm{m} \mathrm{s}^{-1}\right)$
$\mathrm{L}_{1} / \mathrm{L}_{2}=0.33$

(a)
Velocity

contour 1

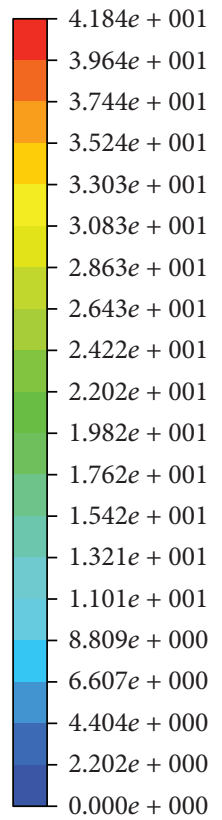

$\left(\mathrm{m} \mathrm{s}^{-1}\right)$
$\mathrm{L}_{1} / \mathrm{L}_{2}=0.5$

(b)
Velocity

contour 1

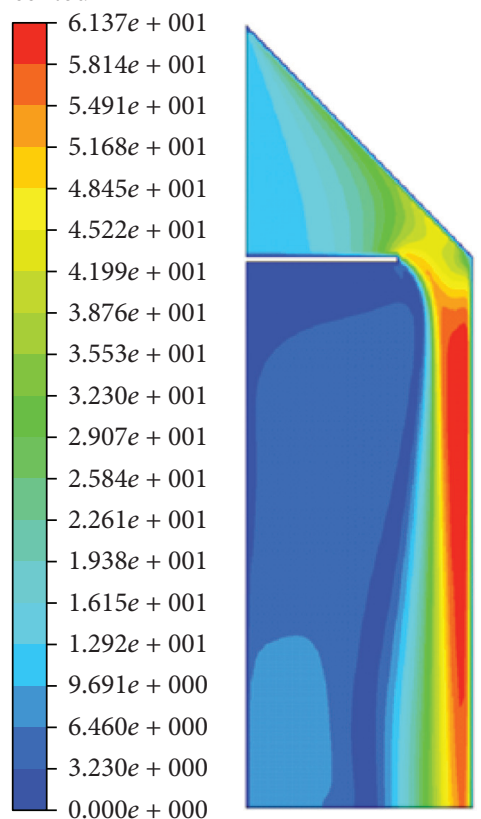

$\left(\mathrm{m} \mathrm{s}^{-1}\right)$

$\mathrm{L}_{1} / \mathrm{L}_{2}=0.66$

(c)

FIGURE 5: Velocity contours at different lengths of slab. (a) $L_{1} / L_{2}=0.33$, (b) $L_{1} / L_{2}=0.5$, and (c) $L_{1} / L_{2}=0.66$.

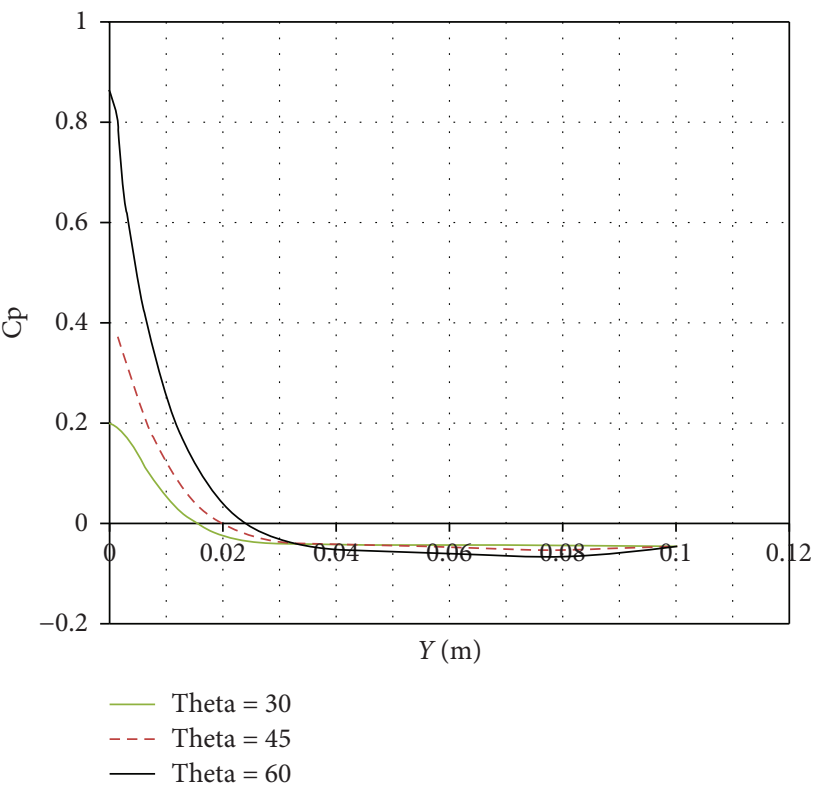

(a)

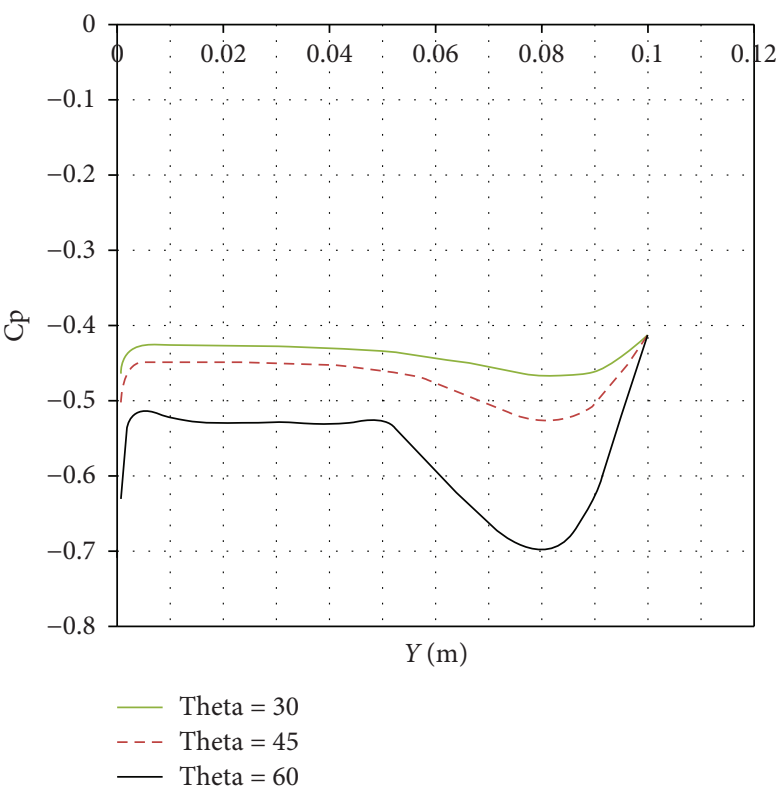

(b)

Figure 6: Effect of slant angle $(\theta)$ on pressure recovery coefficient (Cp) on (a) back wall and (b) side wall of windcatcher.

control system can do such a job easily and in an accurate manner [18]. The computational fluid dynamics can provide the fuzzy system with the required dataset after the required validation of the CFD models [19]. Therefore, a wide range of numerical simulations using the computational fluid dynamics should be performed. The fuzzy logic system can be fed with such data in order to decide intelligently the optimum values of such operating conditions. The higher the 


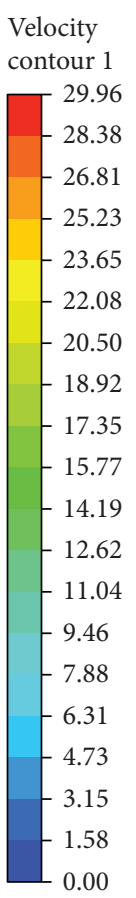

$\left(\mathrm{m} \mathrm{s}^{-1}\right)$

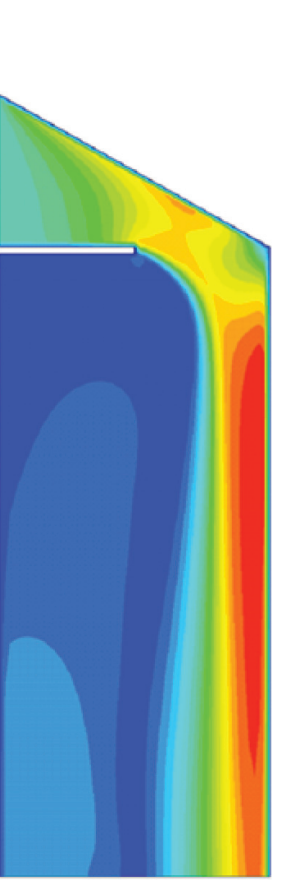

$\theta=30^{\circ}$
Velocity

contour 1

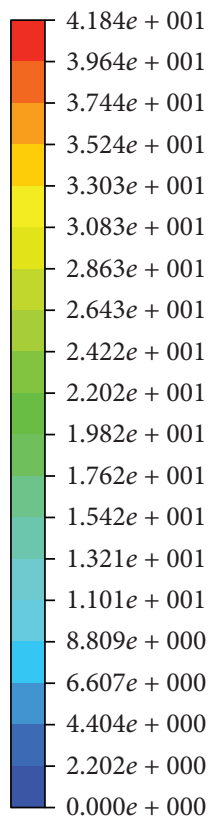

$\left(\mathrm{m} \mathrm{s}^{-1}\right)$

(a)

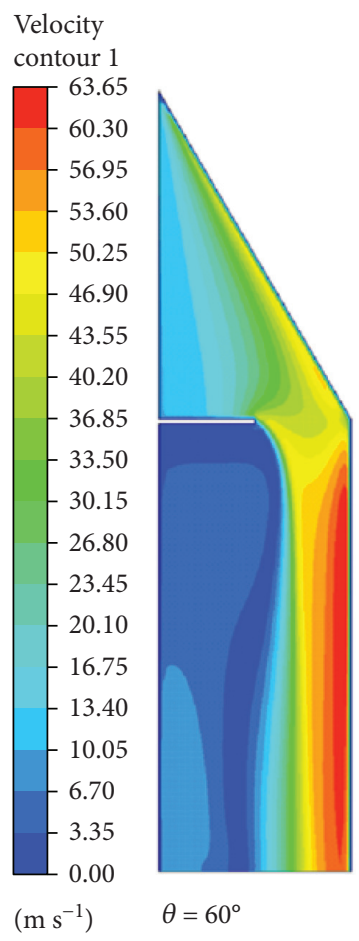

(c)

Figure 7: Velocity contours at different slant angles $(\theta)$.

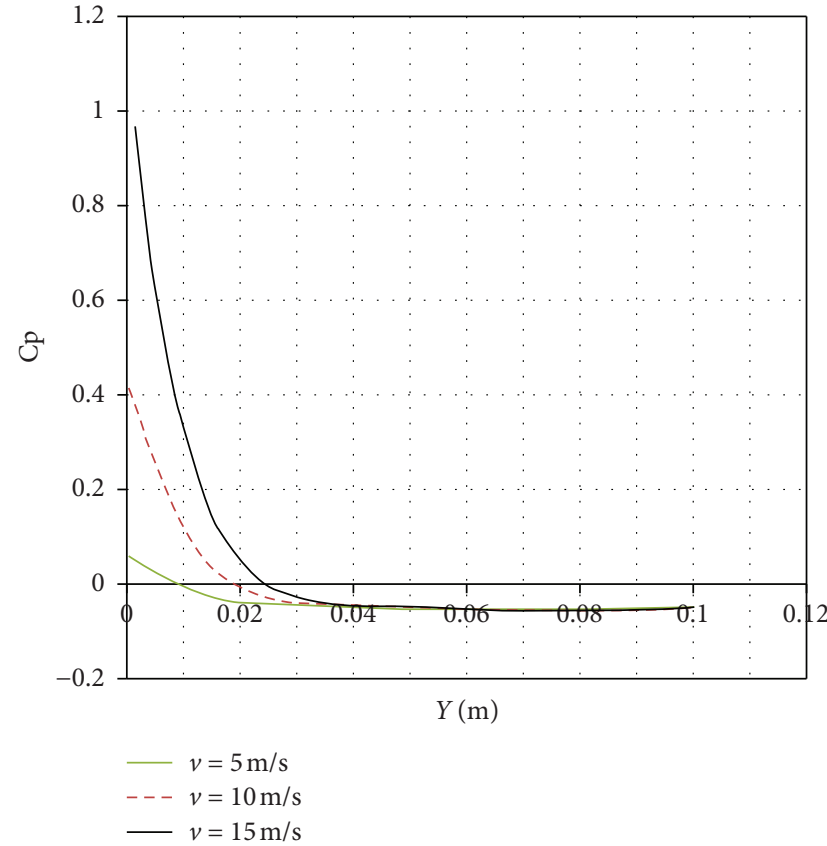

(a)

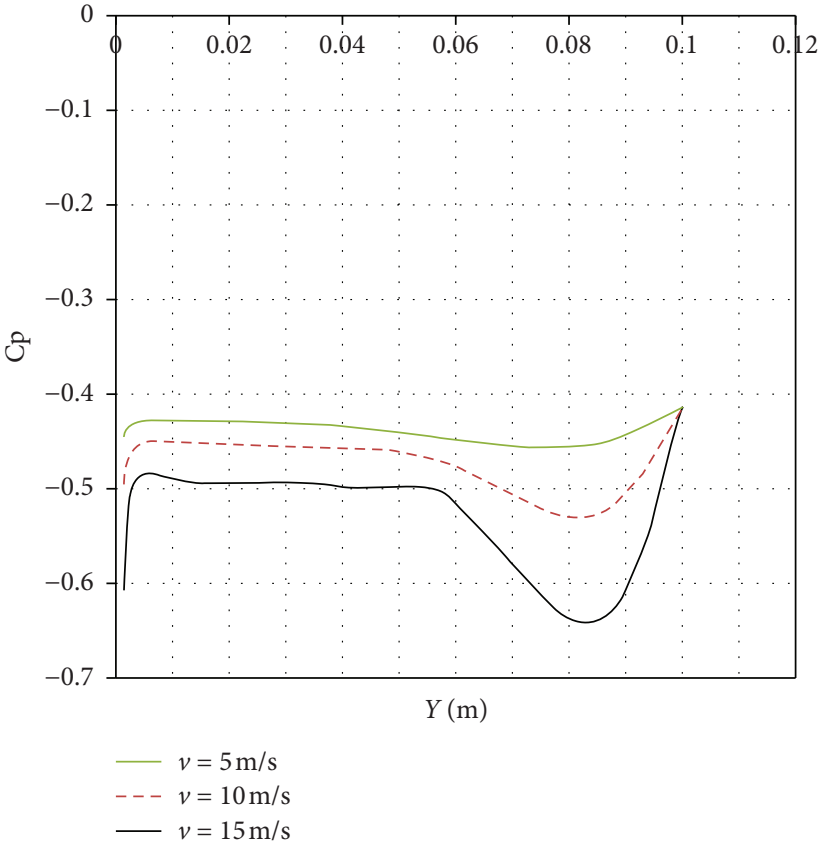

(b)

FIGURE 8: Effect of Reynolds number (Re) on pressure recovery coefficient (Cp) on (a) back wall and (b) side wall of windcatcher.

number of the CFD simulations, the more the correct and optimal decisions from the fuzzy system are obtained. The complete system diagram can be seen in Figure 10.

Figure 11 shows the normalized output of the proposed fuzzy logic system as a function of other operating parameters. It should be pointed out that the proposed fuzzy logic system will be considered in the future work of the problem, as the present work is dedicated for the validation of the numerical procedure and the effectiveness of the proposed internal design of the windcatcher. 


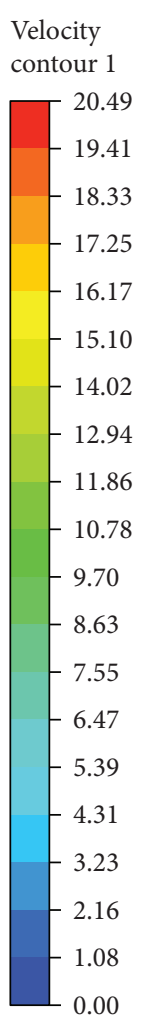

$\left(\mathrm{m} \mathrm{s}^{-1}\right)$

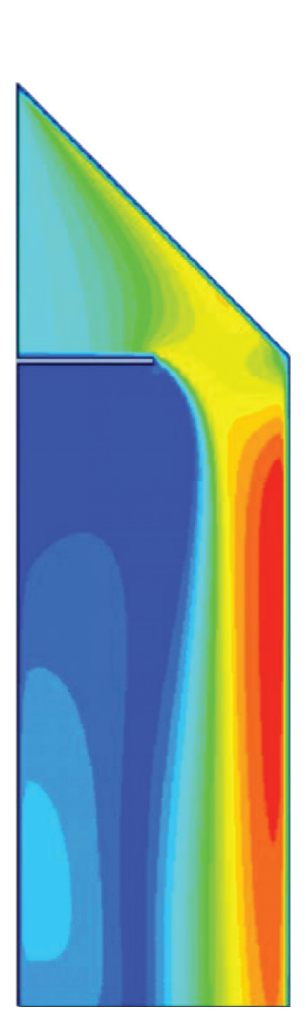

$\operatorname{Re}=25131$

(a)

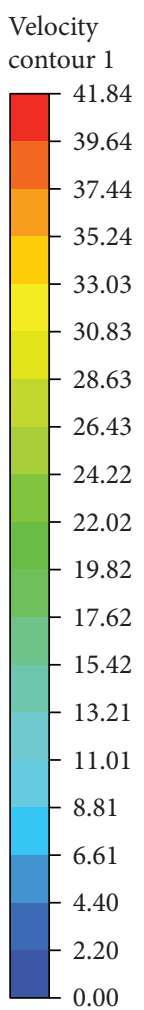

$\left(\mathrm{m} \mathrm{s}^{-1}\right)$

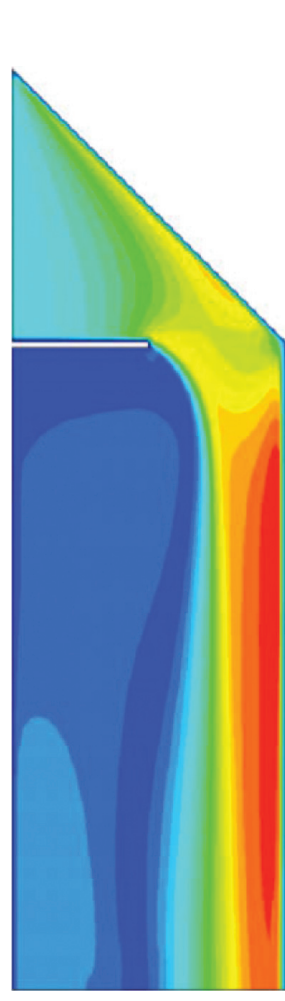

$\operatorname{Re}=50262$

(b)

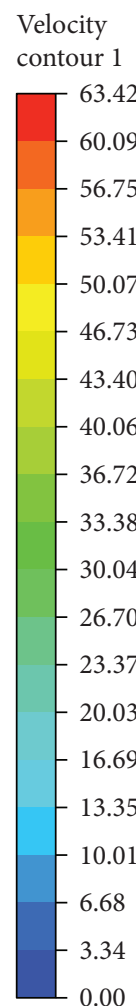

$\left(\mathrm{m} \mathrm{s}^{-1}\right)$

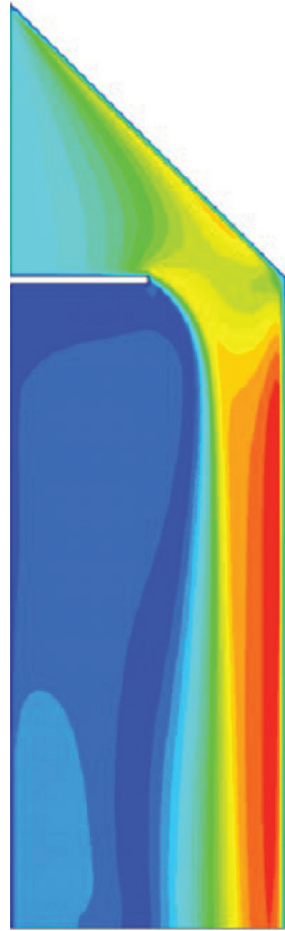

$\operatorname{Re}=75393$

(c)

Figure 9: Velocity contours at different Reynolds number (Re).

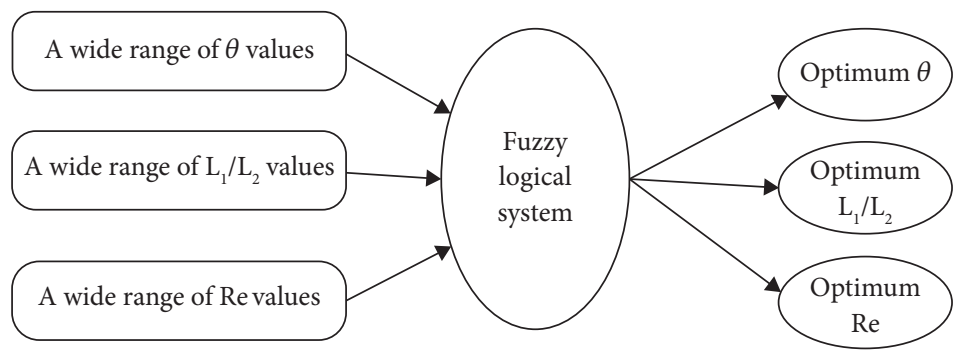

Figure 10: The complete system CFD fuzzy system diagram. 


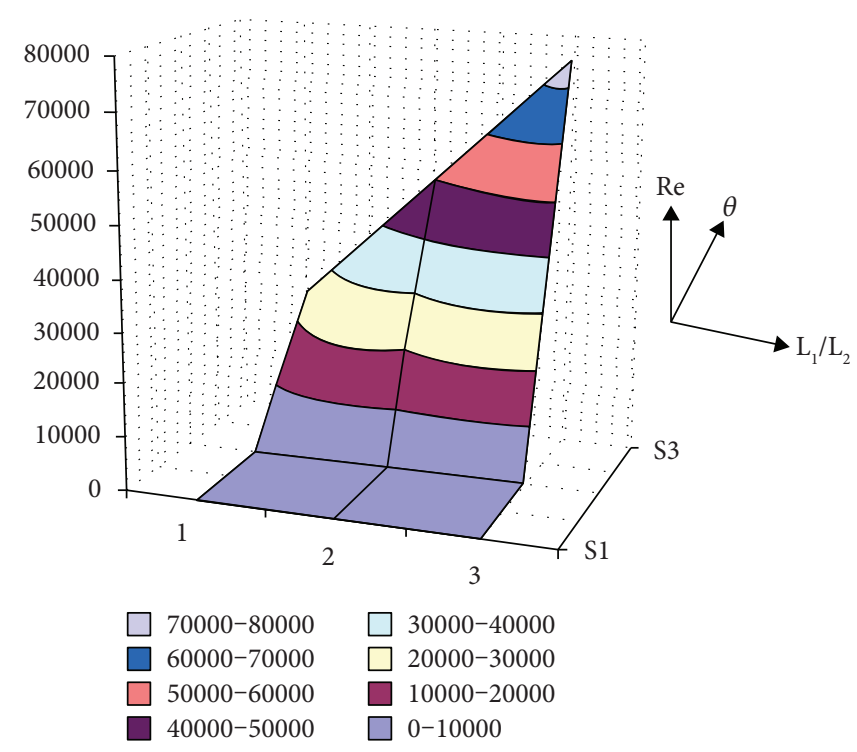

FIgURE 11: The fuzzy control surface.

\section{Conclusions}

In this study, a novel model of windcatcher was proposed to employ in passive cooling of living spaces. The suggested four-way model has openings on four sides that lead the incoming air to the duct downstream. In the present study, only one side of the system is modelled. A slab near the inlet opening was placed to create a nozzle effect to enhance the pressure recovery downstream. The model was studied numerically for the variation of slab length, Reynolds number of incoming wind velocity, and inlet opening to the atmosphere. The data analysis revealed that the introduction of a slab near the inlet improved pressure recovery, which increased with the length of the slab. Higher value of pressure recovery was also observed with increasing opening of inlet section. The effect of Reynolds number on pressure recovery was seen up to a moderate value of Re, after which it did not change significantly. The new model can help in optimizing the design parameters of windcatcher for given local atmospheric conditions. In the future work, the fuzzy logic system will be applied for obtaining the optimum values of the operating parameters.

\section{Data Availability}

No data were used to support this study.

\section{Conflicts of Interest}

The authors declare no conflicts of interest.

\section{References}

[1] F. Jomehzadeh, P. Nejat, J. K. Calautit et al., "A review on windcatcher for passive cooling and natural ventilation in buildings, Part 1: indoor air quality and thermal comfort assessment," Renewable and Sustainable Energy Reviews, vol. 70, pp. 736-756, 2017.
[2] J. K. Calautit, D. O'Connor, P. W. Tien, S. Wei, C. A. J. Pantua, and B. Hughes, "Development of a natural ventilation windcatcher with passive heat recovery wheel for mild-cold climates: CFD and experimental analysis," Renewable Energy, vol. 160, pp. 465-482, 2020.

[3] F. Jomehzadeh, H. M. Hussen, J. K. Calautit, P. Nejat, and M. S. Ferwati, "Natural ventilation by windcatcher (Badgir): a review on the impacts of geometry, microclimate and macroclimate," Energy and Buildings, vol. 226, pp. 465-482, 2020.

[4] M. Hossein Ghadiri, N. Lukman, N. Ibrahim, and M. Farid Mohamed, "Analysis of wind-driven natural ventilation in a two-sided rectangular wind catcher," International Journal of Ventilation, vol. 12, no. 1, pp. 51-62, 2013.

[5] A. Zaki, P. Richards, and R. Sharma, "Analysis of airflow inside a two-sided wind catcher building," Journal of Wind Engineering and Industrial Aerodynamics, vol. 190, pp. 71-82, 2019.

[6] S. Mohammadamin, K. Javad, and G. Navid, "High-performance building: sensitivity analysis for simulating different combinations of components of a two-sided windcatcher," Journal of Building Engineering, vol. 28, 2020.

[7] A. Alzaed and A. Balabel, "A new modern design of four-sided windcatcher for natural ventilation in residential building in Saudi Arabia," International Journal of Applied Environmental Sciences, vol. 12, no. 1, pp. 27-36, 2017.

[8] P. Nejat, J. K. Calautit, M. Z. A. Majid, B. R. Hughes, and F. Jomehzadeh, "Anti-short-circuit device: a new solution for short-circuiting in windcatcher and improvement of natural ventilation performance," Building and Environment, vol. 105, pp. 24-39, 2016.

[9] I. F. S. A. Kabir, S. Kanagalingam, and F. Safiyullah, "Performance evaluation of air flow and thermal comfort in the room with Wind-Catcher using different CFD techniques under neutral Atmospheric Boundary Layer," Energy Procedia, vol. 143, pp. 199-203, 2017.

[10] R. Taghipour, A. Peter, and B. P. Huynh, "Effect of wind speed on ventilation flow through a two dimensional room fitted with a windcatcher," in Proceedings of the ASME International Mechanical Engineering Congress and Exposition, vol. 52101, Pittsburgh, PA, USA, November 2018. 
[11] M. Ghoulem, K. El Moueddeb, E. Nehdi, F. Zhong, and J. Calautit, "Analysis of passive downdraught evaporative cooling windcatcher for greenhouses in hot climatic conditions: parametric study and impact of neighbouring structures," Biosystems Engineering, vol. 197, pp. 105-121, 2020.

[12] M. Farouk, "Comparative study of hexagon \& square windcatchers using CFD simulations," Journal of Building Engineering, vol. 31, p. 101366, 2020.

[13] A. R. Dehghani-Sanij, M. Soltani, and K. Raahemifar, "A new design of wind tower for passive ventilation in buildings to reduce energy consumption in windy regions," Renewable and Sustainable Energy Reviews, vol. 42, pp. 182-195, 2015.

[14] B. E. Launder and D. B. Spalding, "The numerical computation of turbulent flows," Numerical Prediction of Flow, Heat Transfer, Turbulence and Combustion, vol. 3, pp. 269-289, 1974.

[15] D. C. Wilcox, "Formulation of the k-w turbulence model revisited," AIAA Journal, vol. 46, no. 11, pp. 2823-2838, 2008.

[16] F. R. Menter, "Two-equation eddy-viscosity turbulence models for engineering applications," AIAA Journal, vol. 32, no. 8, pp. 1598-1605, 1994.

[17] H. Montazeri and R. Azizian, "Experimental study on natural ventilation performance of one-sided wind catcher," Building and Environment, vol. 43, no. 12, pp. 2193-2202, 2008.

[18] M. Poshtiban, R. Banaei Khosroushahi, and S. Poshtiban, "In intelligent windcatcher-a combination of modern and traditional technology," in Proceedings of the 24 th International Symposium on Automation \& Robotics in Construction, vol. 2007, pp. 126-131, Kochi, India, September 2007.

[19] R. Beigzadeh, “The CFD provides data for adaptive neurofuzzy to model the heat transfer in flat and discontinuous fins," Iranian Journal of Chemical Engineering (IJChE), vol. 16, no. 2, pp. 57-69, 2019. 